\title{
Long noncoding RNA CPS1-IT1 suppresses the metastasis of hepatocellular carcinoma by regulating HIF-1 $\alpha$ activity and inhibiting epithelial-mesenchymal transition
}

\author{
Tong-Hong Wang ${ }^{1,2,3}$, Cheng-Chia Yú ${ }^{4,5,6}$, Yong-Shiang Lin ${ }^{7}$, Tse-Ching Chen ${ }^{7}$, Chau- \\ Ting Yeh ${ }^{8}$, Kung-Hao Liang ${ }^{8}$, Tzong-Ming Shieh ${ }^{9}$, Chi-Yuan Chen ${ }^{2,3}$, Chuen Hsueh ${ }^{1,7}$ \\ ${ }^{1}$ Tissue Bank, Chang Gung Memorial Hospital, Tao-Yuan, Taiwan \\ ${ }^{2}$ Research Center for Industry of Human Ecology, Chang Gung University of Science and Technology, Tao-Yuan, Taiwan \\ ${ }^{3}$ Graduate Institute of Health Industry Technology, Chang Gung University of Science and Technology, Tao-Yuan, Taiwan \\ ${ }^{4}$ School of Dentistry, Chung Shan Medical University, Taichung, Taiwan \\ ${ }^{5}$ Department of Dentistry, Chung Shan Medical University Hospital, Taichung, Taiwan \\ ${ }^{6}$ Institute of Oral Sciences, Chung Shan Medical University, Taichung, Taiwan \\ ${ }^{7}$ Department of Anatomic Pathology, Chang Gung Memorial Hospital, Chang Gung University School of Medicine, Tao-Yuan, \\ Taiwan \\ ${ }^{8}$ Liver Research Center, Department of Hepato-Gastroenterology, Chang Gung Memorial Hospital, Tao-Yuan, Taiwan \\ ${ }^{9}$ Department of Dental Hygiene, College of Health Care, China Medical University, Taichung, Taiwan \\ Correspondence to: Tong-Hong Wang, email: cellww@adm.cgmh.org.tw \\ Chuen Hsueh, email: ch9211@adm.cgmh.org.tw
}

Keywords: long noncoding RNA (IncRNA), hepatocellular carcinoma (HCC), metastasis

Received: January 20, $2016 \quad$ Accepted: May 09, 2016

Published: May 26, 2016

\section{ABSTRACT}

Recently, increasing numbers of long noncoding RNAs (IncRNAs), with both oncogenic and tumor-suppressive potential, have been found to be aberrantly expressed in various human cancers. However, the function of IncRNAs in hepatocellular carcinoma (HCC) progression remains largely unknown. In this study, we performed a comprehensive microarray analysis of IncRNA expression using human HCC specimens. After validation in 119 human HCC tissues, we identified a novel tumor suppressor IncRNA, CPS1 intronic transcript 1 (CPS1-IT1). To elucidate the clinical significance of CPS1-IT1 in HCC, correlations between CPS1IT1 levels, clinical parameters, and survival outcomes were analyzed. In vitro and in vivo functional assays were also performed to dissect the potential underlying mechanisms. Expression of CPS1-IT1 was significantly decreased in $73 \%$ of HCC tissues, and patients with low CPS1-IT1 expression had poor survival outcomes. Furthermore, in vitro functional assays indicated that CPS1-IT1 significantly reduced cell proliferation, migration and invasion capacities through reduced $\mathrm{Hsp} 90$ binding to and activation of HIF-1 $\alpha$, thereby suppressing the epithelial-mesenchymal transition (EMT). An in vivo animal model also demonstrated the tumor suppressor role of CPS1IT1 via decreased tumor growth and metastasis. In conclusion, IncRNA CPS1-IT1 acts as a tumor suppressor in HCC by reducing HIF-1 $\alpha$ activation and suppressing EMT. The findings of this study establish a function for CPS1-IT1 in HCC progression and suggest its potential as a new prognostic biomarker and target for HCC therapy.

\section{INTRODUCTION}

Human hepatocellular carcinoma (HCC) is the most common cancer of the liver and ranks third in cancerrelated death worldwide [1]. According to the annual report of the Department of Health in Taiwan, HCC is also the second-most life-threatening malignancy for both sexes in Taiwan [2-4]. Currently, surgical resection, percutaneous ethanol injection and liver transplantation are the major therapeutic approaches for HCC. For patients 
who are not eligible for resection or those with metastasis, chemotherapy is the primary treatment. However, due to tumor recurrence, metastasis, and poor response to chemotherapy and radiotherapy, the therapeutic response is not satisfactory [5-7]; indeed, the recurrence rate during long-term follow-up is still more than $75 \%$ for patients with resectable HCC $[8,9]$. Thus, it is important to explore new diagnostic and therapeutic molecular targets for HCC.

Previous research into mechanisms underlying tumorigenesis has mainly focused on protein-coding genes. However, recent studies have indicated that non-coding RNAs (ncRNAs) are also involved in regulating various physiologic functions, including tumor development, cell proliferation and migration, and apoptosis [10-12]. For instance, microRNAs (miRNAs), a well-known group of non-coding RNAs, mediate post-transcriptional gene silencing by inducing mRNA degradation or translational inhibition. It is estimated that approximately $30 \%$ of human genes are regulated by miRNAs, and miRNA deregulation is associated with several types of cancer [11, 13-16]. In addition to miRNAs, mounting evidence has indicated that long noncoding RNAs (lncRNAs), which are ncRNAs greater than $200 \mathrm{nt}$, are often deregulated in a wide variety of diseases, including cancer, Alzheimer's disease, and heart disease [17-21]. For example, the IncRNA HOTAIR has been shown to be overexpressed in HCC as well as breast, pancreatic and colon cancers, and HOTAIR can serve as a tumor biomarker [22]. The lncRNA MALAT1, which is overexpressed in esophageal squamous cell carcinoma (ESCC) and glioma, promotes tumor proliferation and metastasis capacity [23, 24], and the IncRNA Sox2ot promotes hepatocellular carcinoma cell metastasis and is correlated with a poor prognosis [25].

Recent studies have estimated that the number of lncRNAs is approximately 15,000, and most lncRNAs exhibit a tissue-specific pattern. Growing evidence has also revealed that $\operatorname{lncRNAs}$ regulate gene expression at different levels, including chromatin reprogramming, transcriptional processing, microRNA sponging and other processes. Thus, investigating the roles of lncRNAs in $\mathrm{HCC}$ may help to further understand HCC carcinogenesis.

Although lncRNAs have been found to be involved in various cellular processes, the functions of lncRNAs in $\mathrm{HCC}$ remain largely unclear. In this study, we identified a novel tumor suppressor lncRNA, CPS1 intronic transcript 1 (CPS1-IT1), by microarray analysis and subsequently validated this finding in $\mathrm{HCC}$ tissue specimens. We found expression of CPS1-IT1 to be significantly reduced in HCC tissues, and patients with low CPS1-IT1 expression had poor survival outcomes. Moreover, CPS1-IT1 could serve as an independent predictor for overall survival and disease-free survival in HCC. Further in vitro and in vivo experiments demonstrated the tumor suppressor role of CPS1-IT1: it reduced tumor growth and metastasis by decreasing Hsp90 binding to and activation of HIF-1 $\alpha$, thereby inhibiting the epithelial-mesenchymal transition. Thus, the findings of this study establish the function of
CPS1-IT1 in HCC progression and suggest its potential as a new prognostic biomarker and target in HCC therapy.

\section{RESULTS}

\section{Identification of IncRNAs deregulated in HCC tissues by microarray analysis}

To screen lncRNAs involved in HCC progression, tumor and non-cancerous normal tissues obtained from three HCC patients were selected for microarray analysis (Affymetrix GeneChip ${ }^{\circledR}$ Human Gene 2.0). We found 84 lncRNAs showing a $>2$-fold change in tumor tissues compared to normal tissues (41 upregulated and 43 downregulated).

To validate these microarray findings, we randomly selected 10 lncRNAs with a fold change $>4$ and validated their expression using quantitative real-time PCR in 15 paired HCC and normal liver samples. We found that the expression of only 5 of $10 \mathrm{lncRNAs}$ was consistent with the microarray results. Among these lncRNAs, we further examined the role of CPS1-IT1 in hepatomagenesis.

\section{CPS1-IT1 expression is decreased in hepatocellular carcinoma}

To elucidate the biological significance of the lncRNA CPS1-IT1 in HCC, we first examined CPS1-IT1 expression in 119 paired $\mathrm{HCC}$ and noncancerous normal liver tissues using quantitative real-time PCR. GAPDH was used as an internal control. The results showed that CPS1-IT1 was reduced in 73\% $(87 / 119$, Figure 1 A, 1B) of HCC tissues compared to normal liver tissues, suggesting a potential role as a tumor suppressor.

\section{Decreased CPS1-IT1 expression is associated with poor prognosis of $\mathrm{HCC}$}

To determine the clinical significance of CPS1-IT1, we further evaluated the correlation between CPS1-IT1 expression and survival outcome in 119 HCC patients. The clinical parameters, including patients' gender, age, carcinogenetic risk factors (HBV or HCV carrier, smoking, and alcoholism), cancer aggressiveness (degree of vascular invasion and capsule invasion), histology grading, tumor size, and serological markers (alpha-fetoprotein (AFP), albumin (Alb), bilirubin, creatinine $(\mathrm{Cr})$, aspartate aminotransferase (AST), and alanine aminotransferase (ALT)) of the recruited HCC cohort are summarized in Table 1 . The patients were first subclassified into high (ratio > 2.65) and low (ratio < 2.65) CPS1-IT1 expression groups, and the data were subjected to Kaplan-Meier survival analysis and a log rank test. The results showed that among the HCC cohort, lower CPS1-IT1 expression in normal tissues resulted in poor disease-free survival and overall survival (Figure 1C-1D). However, higher 
serological Alb and capsule invasion were significantly associated with better disease-free survival and overall survival (Table 2).

To determine potential independent predictors for postoperative survival, a stepwise multivariate Cox proportional hazard model was employed. Higher CPS1IT1 and Alb expression in normal tissues was associated with a reduced lethal risk of $0.55 \times$ and $0.64 \times$, respectively. However, for overall survival, only high CPS1-IT1 expression reduced the lethal risk by $0.57 \times$ (Table 3 ).

\section{CPS1-IT1 acts as a tumor suppressor by suppressing cell proliferation and migration in vitro}

To determine the biological functions of CPS1-IT1 during tumor progression, CPS1-IT1 was overexpressed in $\mathrm{J} 7$ and SK-Hep1 cell lines, and cell proliferation was monitored using an xCELLigence real-time cell analyzer. We found that forced CPS1-IT1 expression significantly reduced proliferation of the SK-Hep1 cell line, inhibiting proliferation capacity by approximately $29.7 \%$ at 84 hours compared to cells transfected with the empty vector $\left(\mathrm{p}<0.01^{* *}\right)$ (Figure 2A). Similarly, colony-formation

(A)

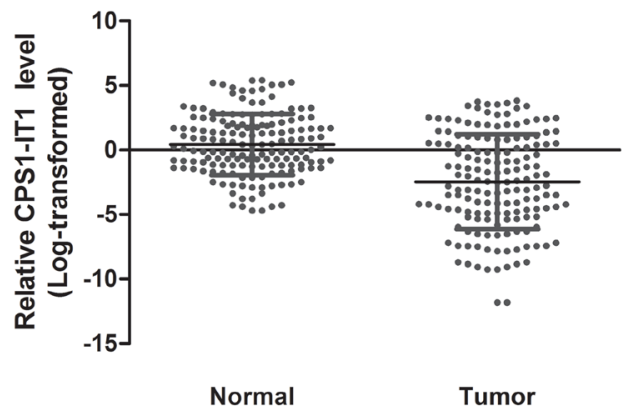

(C)

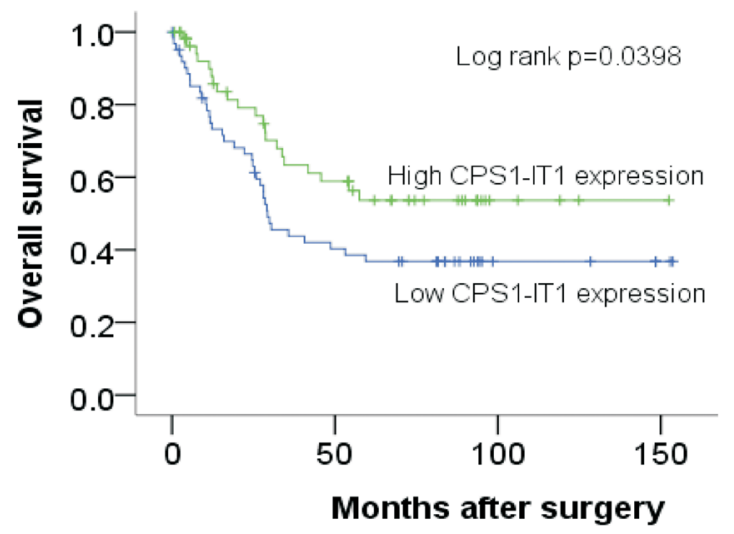

ability was reduced by CPS1-IT1 in both HCC cell lines (Figure 2B). Furthermore, we examined cell migration capacity using transwell and wound healing assays (Figure 2C-2E). The migration capacities of both CPS1IT1-overexpressing cell lines were reduced compared to the control group, and the effects triggered by CPS1-IT1 were significantly rescued by treatment with CPS1-IT1 siRNA (Figure 2F). Similar results were observed in the cell invasion assay, with the invasion capacity of both CPS1-IT1-overexpressing cell lines being reduced by approximately $75 \%$ and $70 \%$, respectively, compared to the control group (Figure $2 \mathrm{G}-2 \mathrm{H}$ ). Taken together, these results suggested that CPS1-IT1 suppressed cancer cell proliferation as well as migration and invasion capacities.

\section{CPS1-IT1 is associated with Hsp90 and inhibits the epithelial-mesenchymal transition}

Occurrence of the epithelial-mesenchymal transition (EMT) during tumorigenesis may increase the motility and invasiveness of cancer cells, and malignant transformation may be associated with signaling pathways that promote EMT [26]. To further investigate associations between EMT and CPS1-IT1 in HCC, we analyzed the expression
(B)

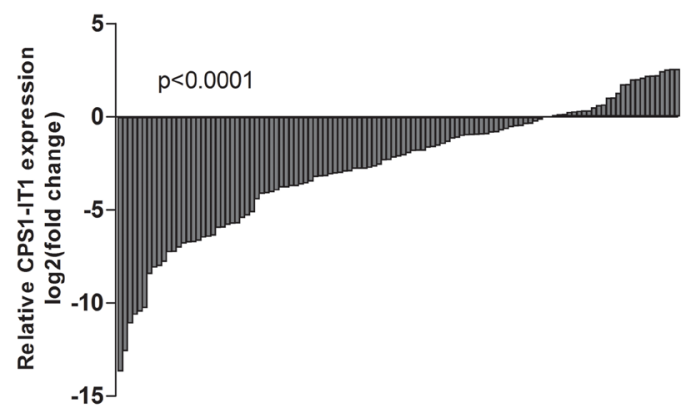

(D)

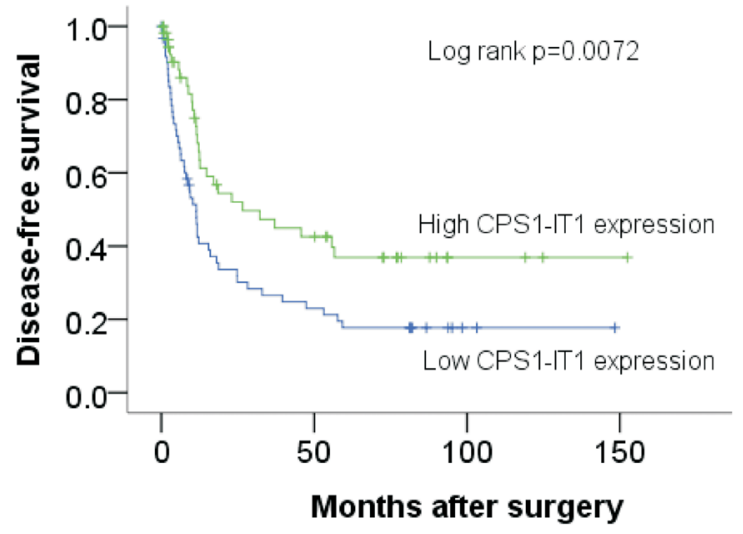

Figure 1: Relative expression of CPS1-IT1 in human hepatocellular carcinoma tissues. A. Relative expression of CPS1-IT1 in 119 HCC tissues compared with corresponding non-cancerous normal tissues. CPS1-IT1 levels were examined using quantitative RTPCR and normalized against GAPDH expression. B. Results are presented as the fold-change in tumor tissues relative to normal tissues. C. and D. Kaplan-Meier analysis of disease-free survival or overall survival according to CPS1-IT1 expression levels was performed. Low CPS1-IT1 expression (relative expression level $<2.65$ ) in tumor tissues was associated with a poor prognostic outcome. 
Table 1: Clinical parameters of the HCC patients included in this study

\begin{tabular}{|c|c|c|}
\hline \multirow{2}{*}{ Clinical parameters } & CPS1-IT1 < 2.65 & CPS1-IT1 > 2.65 \\
\hline & N (\%) & N (\%) \\
\hline Total number of patients & $62(52.1)$ & $57(47.9)$ \\
\hline \multicolumn{3}{|l|}{ Gender } \\
\hline Male & $53(85.5)$ & $48(84.2)$ \\
\hline Female & $9(14.5)$ & $9(15.8)$ \\
\hline \multicolumn{3}{|l|}{ Age } \\
\hline$<55$ & $25(40.3)$ & $20(35.1)$ \\
\hline$>55$ & $37(59.7)$ & $37(64.9)$ \\
\hline \multicolumn{3}{|l|}{ Smoking } \\
\hline Negative & $35(58.3)$ & $36(64.3)$ \\
\hline Positive & $25(41.7)$ & $20(35.7)$ \\
\hline \multicolumn{3}{|l|}{ Alcoholism } \\
\hline Negative & $39(66.1)$ & $39(76.5)$ \\
\hline Positive & $20(33.9)$ & $12(23.5)$ \\
\hline \multicolumn{3}{|l|}{ HBV } \\
\hline Negative & $3(4.8)$ & $2(3.6)$ \\
\hline Positive & $59(95.2)$ & $54(96.4)$ \\
\hline \multicolumn{3}{|l|}{$\mathrm{HCV}$} \\
\hline Negative & $2(3.2)$ & $1(1.8)$ \\
\hline Positive & $60(96.8)$ & $56(98.3)$ \\
\hline \multicolumn{3}{|l|}{ Bilirubin } \\
\hline$<0.9$ & $31(50.0)$ & $32(56.1)$ \\
\hline$>0.9$ & $31(50.0)$ & $25(43.9)$ \\
\hline \multicolumn{3}{|l|}{ AST } \\
\hline$<52$ & $41(67.2)$ & $40(72.7)$ \\
\hline$>52$ & $20(32.8)$ & $15(27.3)$ \\
\hline \multicolumn{3}{|l|}{ ALT } \\
\hline$<111$ & $52(86.7)$ & $46(86.8)$ \\
\hline$>111$ & $8(13.3)$ & $7(13.2)$ \\
\hline \multicolumn{3}{|l|}{ Alb } \\
\hline$<4$ & $28(45.2)$ & $23(40.4)$ \\
\hline$>4$ & $34(54.8)$ & $34(59.7)$ \\
\hline \multicolumn{3}{|l|}{$\mathrm{Cr}$} \\
\hline$<1$ & $22(36.7)$ & $18(32.1)$ \\
\hline$>1$ & $38(63.3)$ & $38(67.9)$ \\
\hline \multicolumn{3}{|l|}{ AFP } \\
\hline$<10$ & $17(27.9)$ & $18(33.3)$ \\
\hline
\end{tabular}

(Continued) 


\begin{tabular}{lcc}
\hline \multirow{2}{*}{ Clinical parameters } & CPS1-IT1 < 2.65 & CPS1-IT1 > 2.65 \\
\cline { 2 - 3 }$>10$ & $\mathbf{N}(\mathbf{\%})$ & $\mathbf{N} \mathbf{( \% )}$ \\
Tumor size & $44(72.1)$ & $36(66.7)$ \\
$<3$ & $22(35.5)$ & $15(26.3)$ \\
$>3$ & $40(64.5)$ & $42(73.7)$ \\
Capsule invasion & & \\
Absence & $6(9.7)$ & $7(12.3)$ \\
Presence & $56(90.3)$ & $50(87.7)$ \\
Vessel invasion & & \\
Absence & $25(40.3)$ & $24(42.1)$ \\
Presence & $37(59.7)$ & $33(57.9)$ \\
Stage & & \\
$<2$ & $43(69.4)$ & $38(66.7)$ \\
$>2$ & $19(30.7)$ & $19(33.3)$ \\
\hline
\end{tabular}

Table 2: Associations between CPS1-IT1 expression, clinical parameters and disease-free survival/overall survival

\begin{tabular}{|c|c|c|c|c|c|c|c|c|c|}
\hline \multirow{2}{*}{$\begin{array}{l}\text { Clinical parameters } \\
\text { CPS1-IT1 expression }\end{array}$} & \multirow{2}{*}{$\mathbf{N}$} & \multicolumn{4}{|c|}{ Disease-free survival (months) } & \multicolumn{4}{|c|}{ Overall survival (months) } \\
\hline & & Mean & \multicolumn{2}{|c|}{$95 \% \mathrm{CI}$} & p-value ${ }^{\#}$ & Mean & \multicolumn{2}{|c|}{$95 \% \mathrm{CI}$} & p-value ${ }^{\#}$ \\
\hline$<2.65$ & 62 & 25.91 & 17.17 & 34.65 & $0.007^{*}$ & 47.62 & 36.12 & 59.13 & $0.040^{*}$ \\
\hline$>2.65$ & 57 & 33.62 & 23.43 & 43.80 & & 46.68 & 36.41 & 56.96 & \\
\hline \multicolumn{10}{|l|}{ Gender } \\
\hline Male & 101 & 28.88 & 21.74 & 36.024 & 0.087 & 46.24 & 38.13 & 54.35 & 0.165 \\
\hline Female & 18 & 33.63 & 14.47 & 52.789 & & 52.40 & 28.32 & 76.49 & \\
\hline \multicolumn{10}{|l|}{ Age } \\
\hline$<55$ & 45 & 29.14 & 17.59 & 40.686 & 0.227 & 53.25 & 39.73 & 66.77 & 0.964 \\
\hline$>55$ & 74 & 29.88 & 21.68 & 38.081 & & 43.48 & 34.19 & 52.77 & \\
\hline \multicolumn{10}{|l|}{ Smoking } \\
\hline Negative & 71 & 27.86 & 20.22 & 35.501 & 0.112 & 43.63 & 34.85 & 52.41 & 0.426 \\
\hline Positive & 45 & 29.96 & 17.60 & 42.314 & & 51.23 & 36.48 & 65.99 & \\
\hline \multicolumn{10}{|l|}{ Alcoholism } \\
\hline Negative & 78 & 29.55 & 21.65 & 37.453 & 0.126 & 48.19 & 38.70 & 57.69 & 0.075 \\
\hline Positive & 32 & 33.18 & 17.81 & 48.554 & & 47.20 & 30.54 & 63.85 & \\
\hline \multicolumn{10}{|l|}{$\mathrm{HBV}$} \\
\hline Negative & 5 & 22.49 & -16.84 & 61.811 & 0.555 & 40.09 & -16.71 & 96.89 & 0.492 \\
\hline Positive & 113 & 30.10 & 23.24 & 36.964 & & 47.65 & 39.77 & 55.53 & \\
\hline \multicolumn{10}{|l|}{$\mathrm{HCV}$} \\
\hline Negative & 3 & 29.38 & -76.81 & 135.576 & 0.841 & 58.72 & -74.69 & 192.13 & 0.621 \\
\hline Positive & 116 & 29.61 & 22.90 & 36.310 & & 46.87 & 39.15 & 54.60 & \\
\hline
\end{tabular}




\begin{tabular}{|c|c|c|c|c|c|c|c|c|c|}
\hline \multirow{2}{*}{ Clinical parameters } & \multirow{2}{*}{$\mathbf{N}$} & \multicolumn{4}{|c|}{ Disease-free survival (months) } & \multicolumn{4}{|c|}{ Overall survival (months) } \\
\hline & & Mean & \multicolumn{2}{|c|}{$95 \% \mathrm{CI}$} & p-value ${ }^{\#}$ & Mean & \multicolumn{2}{|c|}{$95 \% \mathrm{CI}$} & p-value ${ }^{\sharp}$ \\
\hline$<0.9$ & 63 & 26.65 & 18.36 & 34.927 & 0.414 & 41.91 & 32.01 & 51.81 & 0.649 \\
\hline$>0.9$ & 56 & 32.93 & 22.20 & 43.653 & & 53.10 & 41.14 & 65.06 & \\
\hline \multicolumn{10}{|l|}{ AST } \\
\hline$<52$ & 81 & 31.06 & 22.77 & 39.343 & 0.390 & 47.72 & 38.02 & 57.42 & 0.567 \\
\hline$>52$ & 35 & 27.46 & 15.23 & 39.687 & & 47.97 & 34.37 & 61.57 & \\
\hline \multicolumn{10}{|l|}{ ALT } \\
\hline$<111$ & 98 & 30.55 & 22.87 & 38.219 & 0.308 & 46.80 & 37.98 & 55.61 & 0.989 \\
\hline$>111$ & 15 & 24.61 & 8.97 & 40.244 & & 52.89 & 33.25 & 72.54 & \\
\hline \multicolumn{10}{|l|}{ Alb } \\
\hline$<4$ & 51 & 22.42 & 13.13 & 31.707 & $0.036^{*}$ & 35.65 & 25.61 & 45.70 & $0.016^{*}$ \\
\hline$>4$ & 68 & 34.99 & 25.76 & 44.213 & & 55.81 & 45.00 & 66.62 & \\
\hline \multicolumn{10}{|l|}{$\mathrm{Cr}$} \\
\hline$<1$ & 40 & 26.02 & 14.64 & 37.396 & 0.702 & 45.85 & 31.87 & 59.83 & 0.715 \\
\hline$>1$ & 76 & 30.34 & 21.96 & 38.721 & & 46.75 & 37.17 & 56.33 & \\
\hline \multicolumn{10}{|l|}{ AFP } \\
\hline$<10$ & 35 & 36.00 & 21.82 & 50.188 & 0.154 & 50.17 & 34.60 & 65.73 & 0.160 \\
\hline$>10$ & 80 & 27.80 & 20.08 & 35.525 & & 47.25 & 38.03 & 56.48 & \\
\hline \multicolumn{10}{|l|}{ Tumor size } \\
\hline$<3$ & 37 & 36.15 & 22.54 & 49.767 & 0.315 & 55.43 & 40.11 & 70.74 & 0.214 \\
\hline$>3$ & 82 & 26.64 & 19.15 & 34.135 & & 43.45 & 34.66 & 52.24 & \\
\hline \multicolumn{10}{|l|}{ Capsule invasion } \\
\hline Absence & 13 & 10.39 & 1.80 & 18.975 & $0.050^{*}$ & 21.89 & 6.68 & 37.10 & $0.031 *$ \\
\hline Presence & 106 & 31.96 & 24.71 & 39.203 & & 50.27 & 42.03 & 58.51 & \\
\hline \multicolumn{10}{|l|}{ Vessel invasion } \\
\hline Absence & 49 & 33.85 & 23.83 & 43.872 & 0.233 & 47.20 & 36.22 & 58.18 & 0.806 \\
\hline Presence & 70 & 26.62 & 17.71 & 35.544 & & 47.16 & 36.45 & 57.86 & \\
\hline \multicolumn{10}{|l|}{ Stage } \\
\hline$<2$ & 81 & 29.66 & 21.31 & 38.019 & 0.589 & 48.41 & 38.68 & 58.14 & 0.301 \\
\hline$>2$ & 38 & 29.47 & 18.37 & 40.569 & & 44.53 & 31.98 & 57.07 & \\
\hline
\end{tabular}

\#Log rank test.

Table 3: Stepwise multivariate Cox proportional hazard model for independent predictors of postoperative survival

\begin{tabular}{|c|c|c|c|c|}
\hline \multirow{2}{*}{ Factors } & \multicolumn{4}{|c|}{ Multivariate } \\
\hline & HR & & & p-value \\
\hline High CPS1-IT1 $(>2.65$ vs. $<2.65)$ & 0.55 & 0.34 & 0.87 & $0.011^{*}$ \\
\hline Alb $(>4$ vs. $<4)$ & 0.64 & 0.41 & 1.01 & 0.053 \\
\hline \multicolumn{5}{|l|}{ Overall survival } \\
\hline High CPS1-IT1 (> 2.65 vs. $<2.65$ ) & 0.57 & 0.34 & 0.98 & $0.042 *$ \\
\hline
\end{tabular}


(A)

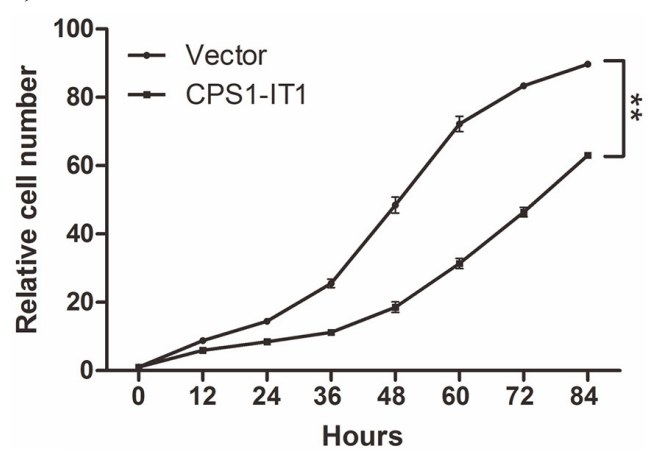

(C)

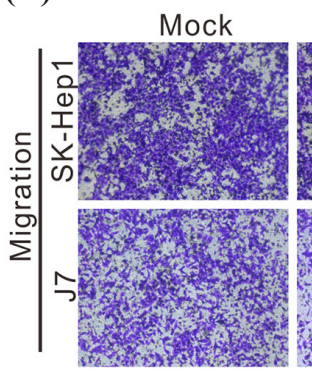

(E)
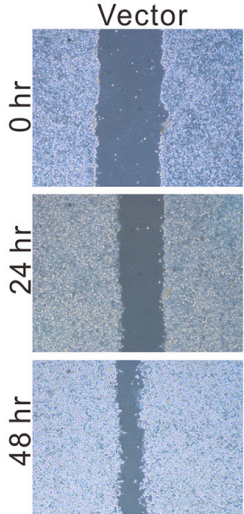

(G)

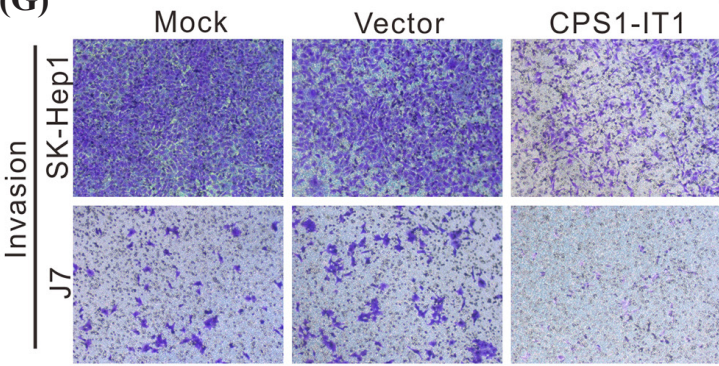

(B)
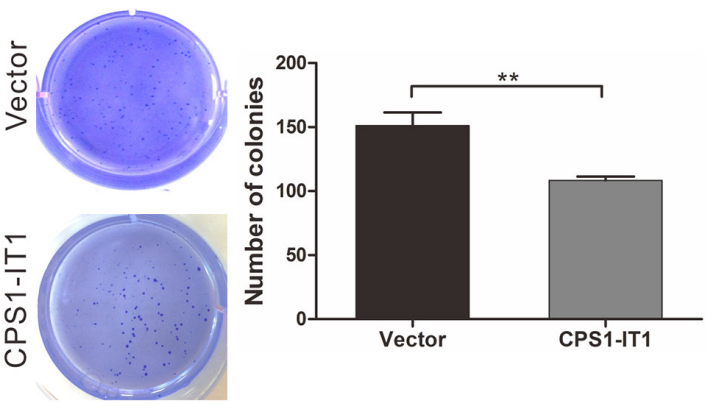

(D)
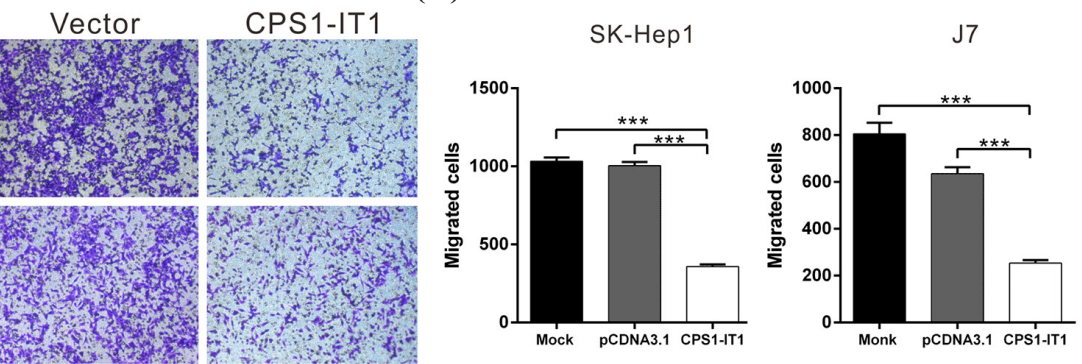

(F)
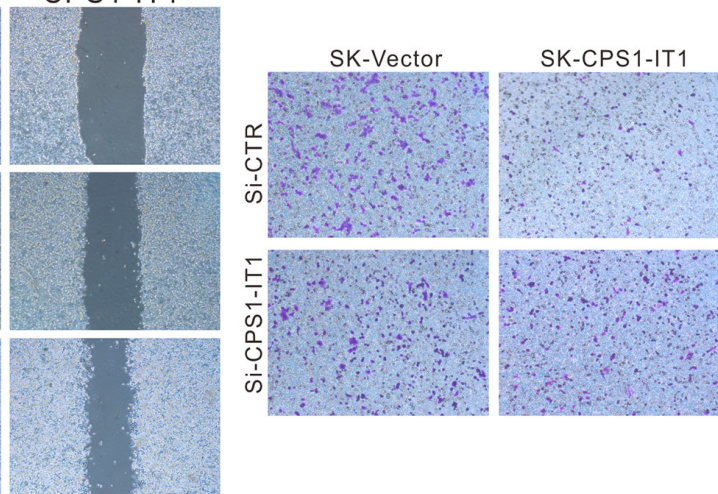

(H)

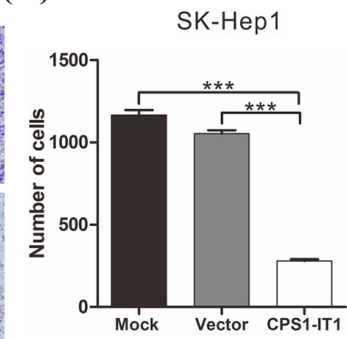

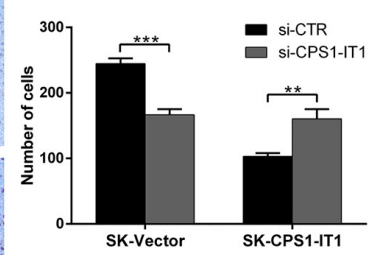

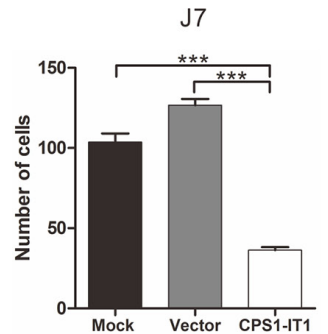

Figure 2: CPS1-IT1 suppresses cell proliferation, migration and invasion in vitro. A. The proliferation capacity of cells was monitored at the indicated time points using an xCELLigence real-time cell analyzer. Forced expression of CPS1-IT1 significantly reduced SK-Hep1 cell growth compared to the vector control at 84 hours. $\mathrm{p}<0.01(* *)$. B. Colony formation ability was analyzed in cells at 12 days after transfection with the CPS1-IT1 plasmid or empty vector. CPS1-IT1 significantly inhibited the colony formation ability of SK-Hep1 cells. C. Cell migration was compared between J7 and SK-Hep1 cells transfected with either the CPS1-IT1 expression plasmid or empty vector. Overexpression of CPS1-IT1 significantly reduced cell migration ability. Quantification of the cell migration assays is presented in D. $p<0.001$ $(* * *)$. E. Results of the wound-healing assay were compared between SK-Hep1 cells transfected with the CPS1-IT1 plasmid or empty vector. Overexpression of CPS1-IT1 inhibited the wound-healing ability of SK-Hep1 cells. F. Cell migration was compared between SK-Hep1 cells overexpressing CPS1-IT1 or with silenced CPS1-IT1 expression. Overexpression of CPS1-IT1 significantly reduced the cell migratory ability, whereas silencing of CPS1-IT1 enhanced the cell migratory capacity (left panel). Quantification of the cell migration assays is shown in the right panel. $\mathrm{p}<0.001(* * *)$. G. Invasion assays were performed with SK-Hep-1 and J7 cells on Matrigel-coated polyethylene terephthalate membrane inserts. Five different $200 \times$ fields were imaged to quantify migrating or invading cells. Quantification of the invasive cells is shown in $\mathbf{H}$. 
patterns of EMT-associated proteins, including E-cadherin, $\mathrm{N}$-cadherin, occludin, vimentin, snail, and twist, in the SK-Hep1 cell line. Expression of the EMT-promoting proteins N-cadherin, vimentin, snail, and twist was reduced in CPS1-IT1-overexpressing cells, whereas the levels of E-cadherin and occludin were increased (Figure 3A). These results suggested that CPS1-IT1 exerted its tumor suppressive effects by inhibiting EMT.

Recent studies have indicated that IncRNAs can bind to proteins and alter their functions; these molecules are thus involved in regulating a variety of biological processes $[27,28]$. To further characterize the potential mechanism of CPS1-IT1 in EMT inhibition, an RNA pull-down assay followed by LC-MASS analysis was performed. As shown in Table 4, several proteins, including heat shock protein 90 (Hsp90), heat shock protein 70 (Hsp70) and the neuroblast differentiationassociated protein AHNAK, were identified. To further validate associations between CPS1-IT1 and these proteins, an RNA immunoprecipitation (RIP) assay was performed using antibodies against these proteins. Significantly higher enrichment of CPS1-IT1 was observed with the anti-Hsp90 antibody compared with a non-specific IgG control KCNH2 antibody (Figure 3B). These results indicated a high level of association between CPS1-IT1 and Hsp90.

\section{CPS1-IT1 acts as a co-chaperone and alters Hsp90 and HIF-1 $\alpha$ binding affinity}

The protein chaperone Hsp90 is a major regulator of the activities of different transcription factors. It has been previously demonstrated that Hsp90 promotes EMT in colorectal cancer via activation of HIF-1 $\alpha$, which results in a subsequent downregulation of Hsp90, leading to inhibition of EMT, motility, and invasiveness [29, 30].
(A)

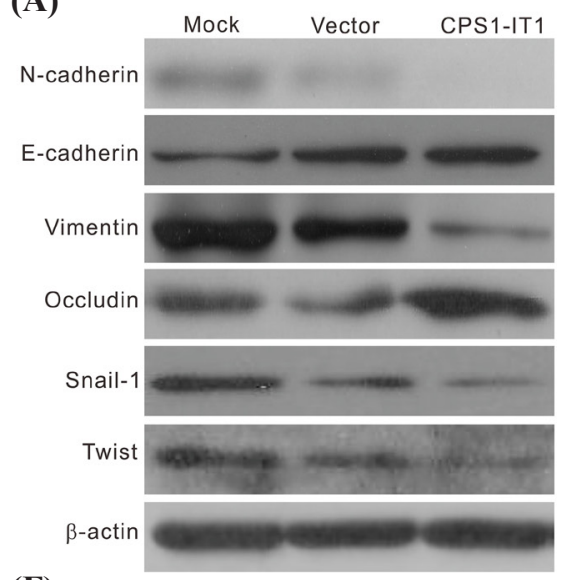

(F)
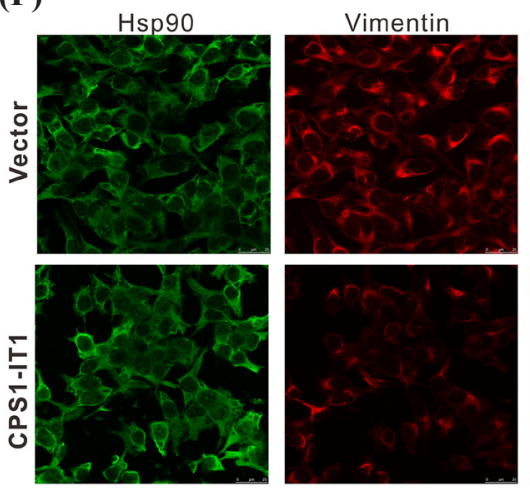

(B)

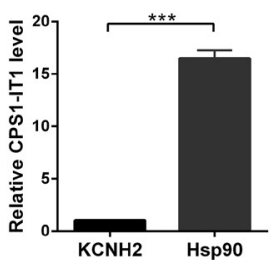

(D)

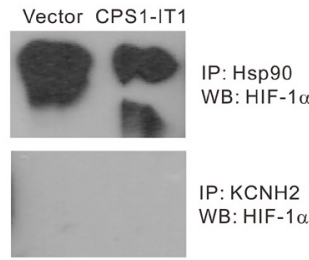

(C)
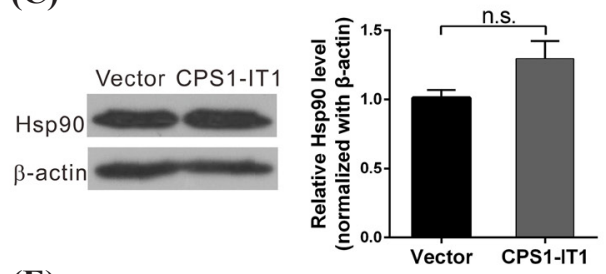

(E)
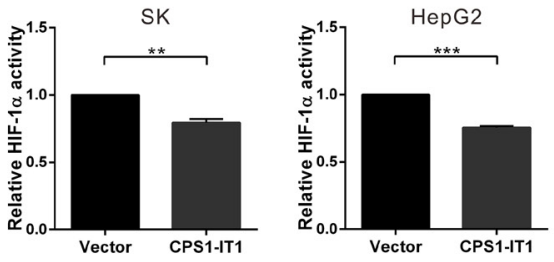

(G)

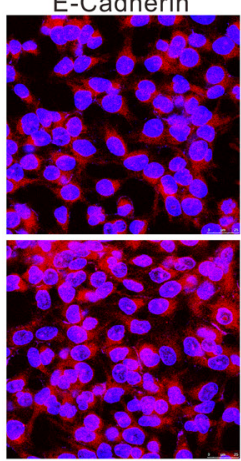

DAPI

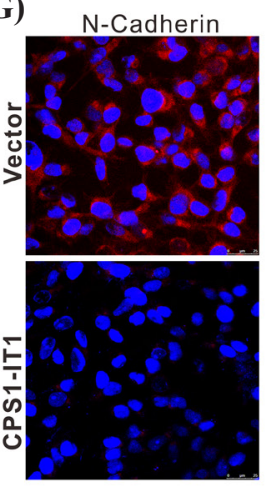

E-Cadherin
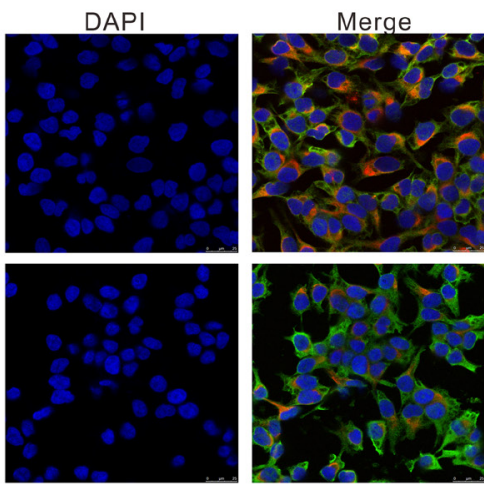

Figure 3: CPS1-IT1 associates with Hsp90 and inhibits the epithelial-mesenchymal transition. A. Western blotting analysis of EMT-associated proteins after CPS1-IT1 plasmid or empty vector transfection. $\beta$-Actin served as the internal control. B. RIP experiments were performed on SK-Hep1 cell lysates using an antibody against Hsp90. The KCNH2 antibody served as a negative control. Purified RNA was subjected to qRT-PCR for CPS1-IT1 detection. The results revealed an association between CPS1-IT1 and Hsp90. C. Western blotting analyses revealed the levels of Hsp90 in SK-Hep1 cells transfected with the CPS1-IT1 plasmid or vector only. Overexpression of CPS1-IT1 did not affect the protein levels of Hsp90. D. Binding affinity between Hsp90 and HIF-1 $\alpha$ was analyzed using a co-immunoprecipitation assay. CPS1-IT1 reduced the binding between Hsp90 and HIF-1 $\alpha$. E. HIF-1a activity was analyzed using a dual luciferase reporter assay. CPS1-IT1 reduced the activity of HIF-1 $\alpha$ in SK-Hep1 and HepG2 cells. F. and G. Expression of Hsp90 and EMT-associated proteins in SK-Hep1 cells after CPS1-IT1 plasmid or empty vector transfection was examined using immunofluorescence staining. CPS1-IT1 reduced vimentin and $\mathrm{N}$-cadherin expression but did not affect Hsp90 levels. 
Table 4: Mass spectrometry analysis of the proteins pulled down by the IncRNA CPS1-IT1

\begin{tabular}{|c|c|c|c|c|c|c|}
\hline Hits & Description & Protein score & Protein mass (Da) & PSMs & Peptides & Protein coverage $\%$ \\
\hline 1 & $\begin{array}{l}\text { Neuroblast } \\
\text { differentiation- } \\
\text { associated protein } \\
\text { AHNAK }\end{array}$ & 3013 & 629,213 & 74 & 43 & 11.3 \\
\hline 2 & $\begin{array}{l}\text { Heat shock protein } \\
\text { HSP 90-beta }\end{array}$ & 2057 & 83,554 & 58 & 22 & 30.9 \\
\hline 3 & $\begin{array}{l}\text { Heat shock } \\
\text { cognate } 71-\mathrm{kDa} \\
\text { protein }\end{array}$ & 1933 & 71,082 & 49 & 20 & 33.3 \\
\hline 4 & $\begin{array}{l}\text { Heat shock protein } \\
\text { HSP 90-alpha }\end{array}$ & 1841 & 85,006 & 48 & 19 & 28.4 \\
\hline 5 & Filamin-A & 1543 & 283,301 & 39 & 23 & 12.3 \\
\hline 6 & $\begin{array}{l}78-\mathrm{kDa} \text { Glucose- } \\
\text { regulated protein }\end{array}$ & 1502 & 72,402 & 37 & 19 & 34.3 \\
\hline 7 & $\begin{array}{l}60-\mathrm{kDa} \text { heat } \\
\text { shock protein, } \\
\text { mitochondrial }\end{array}$ & 1500 & 61,187 & 34 & 15 & 35.3 \\
\hline 8 & Filamin-C & 1491 & 293,407 & 35 & 19 & 9.8 \\
\hline 9 & Myosin-9 & 1428 & 227,646 & 30 & 17 & 10.8 \\
\hline 10 & $\begin{array}{l}\text { Stress- } 70 \text { protein, } \\
\text { mitochondrial }\end{array}$ & 1418 & 73,920 & 33 & 16 & 31.2 \\
\hline
\end{tabular}

To further validate the regulation of Hsp90 by CPS1IT1, we examined whether CPS1-IT1 affects the stability of Hsp90 using western blotting analysis. However, we did not observe any difference in Hsp90 levels between cells transfected with the CPS1-IT1 plasmid or empty vector (Figure 3C). The same results were also observed using an immunofluorescence staining assay. Although CPS1-IT overexpression reduced the expression of EMTpromoting proteins such as $\mathrm{N}$-cadherin and vimentin, Hsp90 expression was not altered (Figure 3F-3G). Taken together, these results suggested that CPS1-IT1 did not regulate the stability of Hsp90.

To investigate whether CPS1-IT1 is involved in Hsp90-mediated HIF-1 $\alpha$ activation, the binding affinity between Hsp90 and HIF-1 $\alpha$ was analyzed using a coimmunoprecipitation assay. As shown in Figure 3D, HIF-1 $\alpha$ co-immunoprecipitated with Hsp90; however, a significant reduction in the interaction between HIF-1 $\alpha$ and Hsp90 was detected in cells overexpressing CPS1IT1. Hsp90 levels on the same blot were also analyzed, demonstrating that a similar amount of Hsp90 was immunoprecipitated in each sample (data not shown). Furthermore, HIF-1 $\alpha$ activity was examined, and we found reductions in CPS1-IT1-overexpressing cells compared to the control group (Figure 3E). These results indicated that
CPS1-IT1 interacted with Hsp90 and reduced the binding affinity between Hsp90 and HIF-1 $\alpha$, thereby resulting in reduced HIF-1 $\alpha$ activation. Inactivation of HIF- $1 \alpha$ resulted in decreased expression of EMT-related proteins.

\section{CPS1-IT1 suppresses tumor growth and metastasis in vivo}

To further validate the tumor suppressor role of CPS1-IT1 in HCC, in vivo xenograft and tail injection migration assays were performed. Consistent with previous results, the growth of tumors from CPS1-IT1 xenografts was significantly reduced compared with the control group at 21 days after injection (Figure 4A, 4B). An inhibitory effect of CPS1-IT1 on HCC lung metastasis was also observed (Figure 4C, 4D). Immunohistochemical staining was performed to confirm the regulation of EMT by CPS1-IT1. Similar to the results obtained in the in vitro cell assay, expression of EMT-promoting proteins, such as vimentin and $\mathrm{N}$-cadherin, was decreased in CPS1-IT1-overexpressing tumors, whereas expression of E-cadherin was increased. No differences in the levels of Hsp90 between the CPS1-IT1-overexpressing and control groups were observed (Figure 4E). 


\section{DISCUSSION}

In addition to microRNAs, IncRNAs have emerged as important factors in cell biology. Evidence to date links lncRNA dysregulation to diverse human diseases, including cancers [31-34]. However, the function of
lncRNAs in HCC progression remains largely unknown. In this study, we identified a novel tumor suppressor lncRNA: CPS1-IT1. Expression of CPS1-IT1 was significantly reduced in HCC tissues, and low CPS1IT1 expression was correlated with poor outcomes. In vitro functional assays and an in vivo animal model
(A)

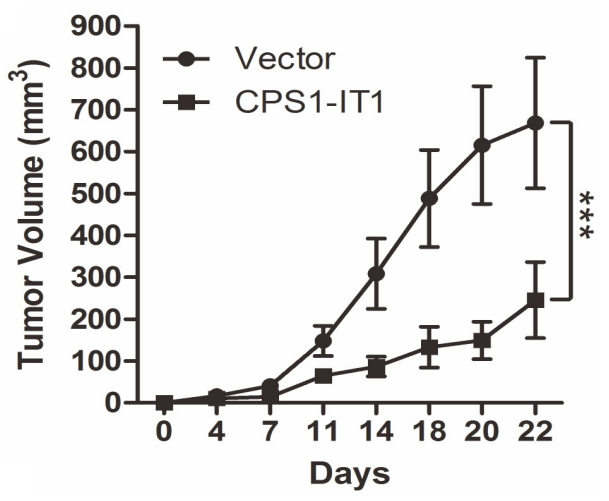

(C)

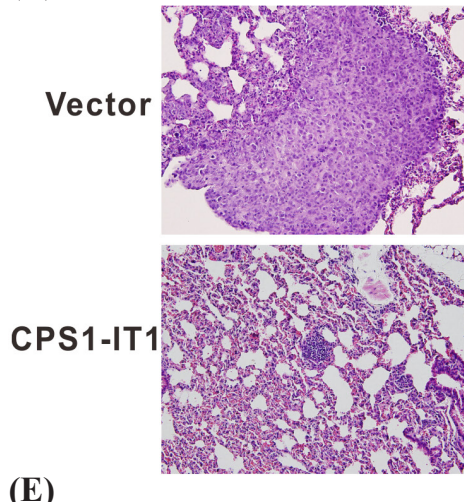

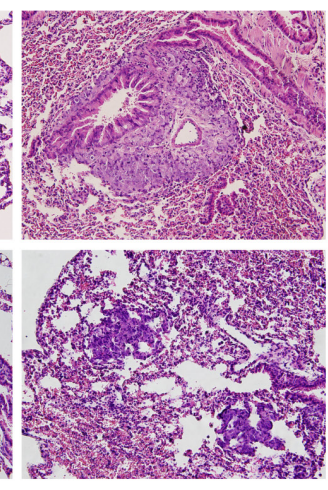

$\mathrm{N}$-cadherin
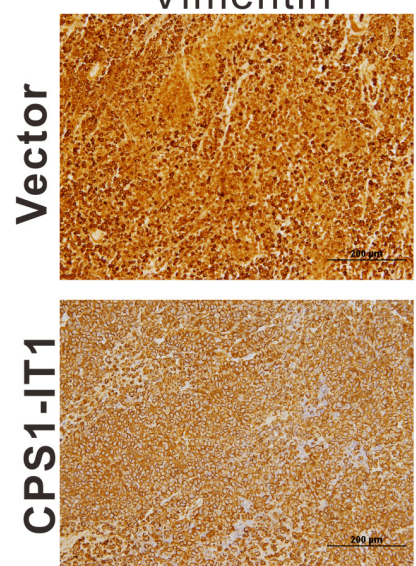

(B)

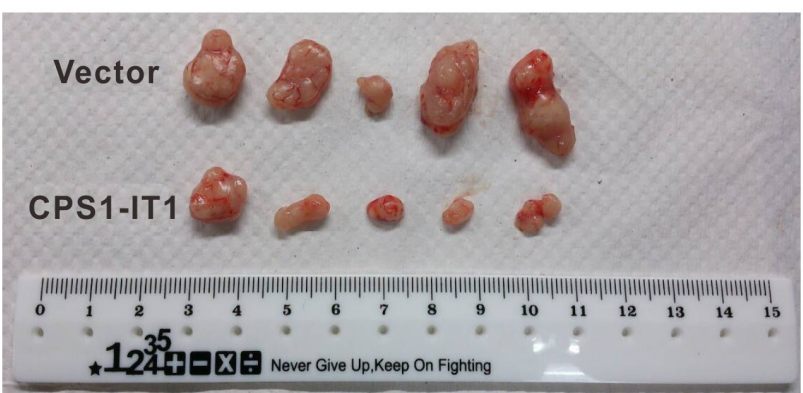

(D)
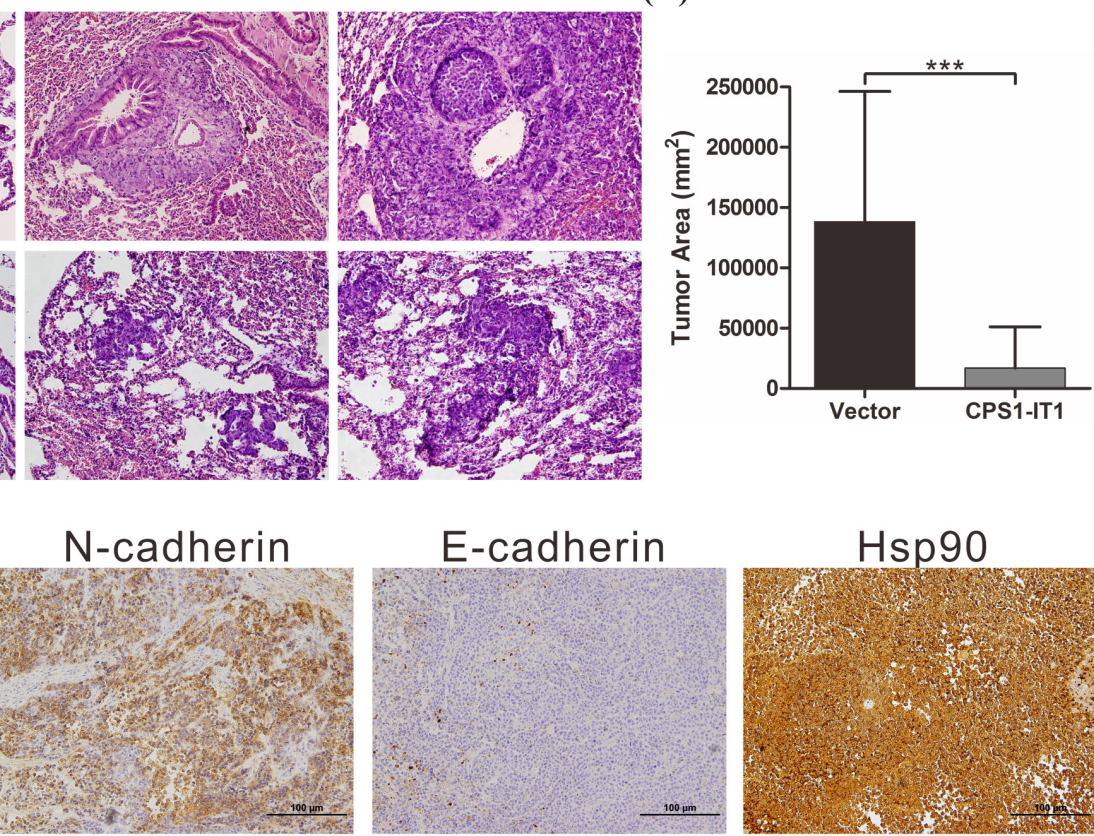

E-cadherin
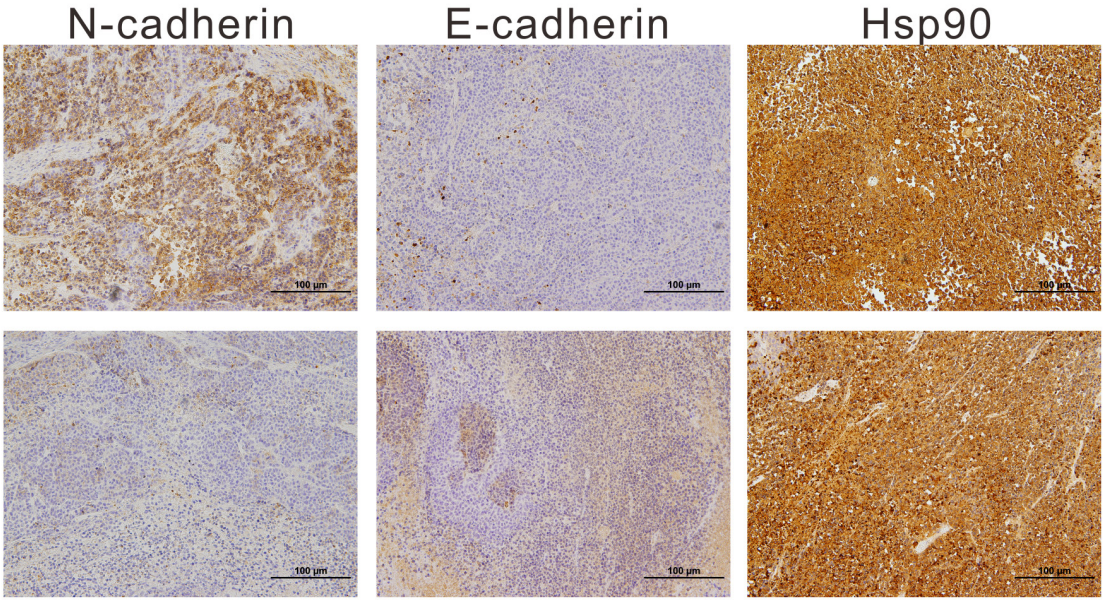

Figure 4: CPS1-IT1 reduces tumor growth and metastasis of HCC cells in vivo. A. SK-Hep1 cells stably transfected with pCDNA3.1-CPS1-IT1 or empty vector were inoculated into nude mice $(n=5)$. Tumor volumes were calculated every 3 days after injection. Bars indicate S.D. B. Representative images showing the tumor xenografts at 4 weeks after implantation. CPS1-IT1 expression significantly reduced tumor growth. C. Representative images of lung metastasis as illustrated by H\&E staining in nude mice at 6 weeks after tail vein injection with SK-Hep1 cells stably transfected with pCDNA3.1 or pCDNA3.1-CPS1-IT1. CPS1-IT1 significantly reduced tumor metastasis. Magnification: 200×. D. Histological analysis of lung tumor volume in the control and CPS1-IT1-overexpressing groups. The mean \pm S.D. is shown. $(\mathrm{n}=5) .{ }^{* *} \mathrm{p}<0.01,{ }^{* * *} \mathrm{p}<0.001$. E. CPS1-IT1 reduced the expression of EMT-promoting proteins, as assessed using immunohistochemical staining. 
demonstrated that CPS1-IT1 reduced cell proliferation as well as migration and invasion capacities, thereby suppressing EMT. Together, these findings indicated that CPS1-IT1 functions as a tumor suppressor in HCC and may serve as a prognostic marker for HCC.

Invasion and metastasis are the main causes of cancer-related mortality, and EMT is well known to increase the motility and invasiveness of cancer cells [35, 36]. In this study, we observed that CPS1-IT1 significantly reduced cell migration and invasion capacities. Furthermore, expression of EMT-promoting proteins, such as $\mathrm{N}$-cadherin, vimentin, snail and twist, was significantly reduced in CPS1-IT1-overexpressing cells. These results indicated that CPS1-IT1 could decrease HCC invasion and metastasis by suppressing EMT. This finding was further supported by prognostic analysis. Decreased CPS1-IT1 expression was associated with shorter metastasis-free and overall survival after surgery in HCC patients, supporting the hypothesis that CPS1-IT1 can serve as a molecular prognostic factor that can be used to identify high-risk patients for further intense treatment.

The molecular mechanisms of lncRNAs are diverse. lncRNAs can function in the following ways: (i) as a decoy to locate transcription factors; (ii) as a regulatory signal for transcription; (iii) as a scaffold to bridge different proteins; (iv) as a 'sponge' to sequester microRNAs; (v) as a guide for proteins to reach their targets; and (vi) as a modified protein that can allosterically alter the functions of other proteins [37, 38]. For instance, the lncRNA CCND1 allosterically regulates the activation of TLS [39], and the IncRNA rncs-1 modulates the expression of Dicer-regulated genes [40]. In addition, sno-lncRNAs strongly associate with Fox family splicing regulators to alter splicing patterns. Similar to CCND1, we found that CPS1-IT1 interacts with Hsp90, a dimeric molecular chaperone that is required for the activation and stabilization of numerous proteins; many of these proteins are involved in essential cellular processes, such as signal transduction pathways [41, 42]. The activation process is regulated by large ATP-induced conformational changes, co-chaperones and posttranslational modifications. In eukaryotic cells, more than 20 co-chaperones have been identified as regulating the function of $\mathrm{HspP} 90$ in various ways, such as inhibition and activation of its ATPase activity as well as recruitment of specific client proteins. In addition to promoting EMT in colorectal cancer via activation of HIF-1 $\alpha$ by Hsp90 [29], several reports have also demonstrated that Hsp90 promotes $\alpha$-SMA and p-p38 expression and reduces that of E-cadherin in $\mathrm{HCC}$ cells, thereby promoting EMT. Consistent with these findings, we suggest that based on the EMT suppression effects of CPS1-IT, this lncRNA may act as an Hsp90 co-chaperone, thereby altering the conformation of Hsp90 and its binding affinity toward HIF- $1 \alpha$. According to our results, inactivation of HIF- $1 \alpha$ resulted in decreased expression of EMT-associated proteins.
DNA methylation at gene promoters is crucial for gene silencing and may function as an epigenetic regulator of $\operatorname{lncRNA}$ expression. For instance, the lncRNA MEG3, the expression of which is indirectly regulated by mir-29a in HCC cells, inhibits the activity of DNA methyltransferase and reduces MEG3 expression [43, 44]. Thus, further studies on promoter hypermethylation are required to determine the upstream regulatory mechanisms of decreased CPS1-IT expression in HCC.

In conclusion, we identified a long noncoding RNA named CPS1-IT1 and established its tumor suppressor role in HCC carcinogenesis. To the best of our knowledge, this is the first study to address the function of CPS1IT1 in HCC. Taken together, our results provide new insight into the role of IncRNAs in the development of HCC and support the notion that CPS1-IT1 may serve as a prognostic biomarker and a potential therapeutic molecular target for the treatment of HCC.

\section{MATERIALS AND METHODS}

\section{Tissues}

The human HCC and corresponding non-cancerous normal tissues used in this study were obtained from 119 HCC patients who underwent surgical resection at Lin-Kou Chang Gung Memorial Hospital between 2000 and 2012. Clinical and pathological characteristics were obtained from patient charts. Tumors were staged according to the seventh edition of the American Joint Committee on Cancer, and the histological grade was scored according to World Health Organization classification criteria. This study was approved by the Ethics Committee of Chang Gung Memorial Hospital, and written informed consent was obtained from each patient.

\section{Cell lines, antibodies, siRNAs and plasmid construction}

The HCC cell lines J7, HepG2, and SK-Hep1 were cultured in DMEM medium containing 10\% fetal bovine serum at $37^{\circ} \mathrm{C}$ in a $5 \% \mathrm{CO}_{2}$ atmosphere. Polyclonal antibodies against Hsp90, HIF-1 $\alpha$, E-cadherin, N-cadherin, vimentin, occludin, twist, snail and $\beta$-actin were purchased from Genetex (Irvine, CA) and Cell Signaling Technology (Beverly, MA). Secondary antibodies were purchased from Santa Cruz Biotechnology (Santa Cruz, CA). All siRNAs were purchased from Applied Biosystems (Foster City, CA). pCDNA3.1-CPS1-IT1, a CMV-based expression and neomycin-selective plasmid containing lncRNA-CPS1IT1, was constructed by GenScript Co. (Piscataway, NJ).

\section{Generation of stable cell lines}

For the production of stable clones, cell lines were seeded in $10-\mathrm{cm}$ dishes at a density of $1 \times 10^{6}$ cells/well and 
grown overnight; the cells were then transfected with 3 $\mu \mathrm{g}$ of either pCDNA3.1-CPS1-IT1 or pCDNA3.1 plasmid using Lipofectamine 2000 (Invitrogen, Carlsbad, CA). Twenty-four hours after transfection, the medium was replaced with fresh medium containing $0.8 \mathrm{mg} / \mathrm{ml} \mathrm{G} 418$, and the cells were cultured and selected in this cloning medium for 4 weeks. Well-separated colonies were harvested using cloning cylinders and trypsinization; the cells were transferred to 24-well plates, and the cultures were further expanded. Once actively growing, clone stocks were routinely maintained in culture medium supplemented with $0.8 \mathrm{mg} / \mathrm{ml} \mathrm{G} 418$.

\section{Microarray analysis}

Total RNA from tumor and non-cancerous normal tissues obtained from three HCC patients was isolated using the TRIzol reagent (Invitrogen, Carlsbad, CA), amplified and transcribed into cDNA. The biotinylated cDNA was hybridized to the Human Gene 2.0 ST Array (Affymetrix, Santa Clara, CA), as performed by Chang Gung Memorial Hospital Genomics Center (Taiwan), following the manufacturer's instructions. The microarray data were analyzed using Transcriptome Analysis Console (TAC) software version 3.0 (Affymetrix).

\section{Detection of the IncRNA CPS1-IT1 in HCCs using quantitative real-time RT-PCR}

Total RNA from each tissue was isolated using an RNeasy mini kit (QIAGEN, Gaithersburg, MD, USA), followed by treatment with RQ1 RNase-free DNase (Promega, Madison, WI) according to the manufacturer's instructions. Two micrograms of treated RNA sample was subjected to reverse transcription (RT). The RT product was subjected to quantitative real time RT-PCR for detection of lncRNA CPS1-IT1 expression using the TaqMan non-coding RNA expression assay (Applied Biosystems, Foster City, CA); GAPDH was used as an internal control.

\section{Transfection and western blotting analysis}

Cell lines were seeded overnight in 6-well plates at a density of $3 \times 10^{5}$ cells/well. The cells were transfected with $1 \mu \mathrm{g}$ of either pCDNA3.1-CPS1-IT1 or pCDNA3.1 plasmid using Lipofectamine 2000 (Invitrogen, Carlsbad, CA) according to the manufacturer's instructions. Fortyeight hours later, the transfected cells were washed twice with PBS and lysed in $200 \mu$ of RIPA lysis buffer (50 $\mathrm{mM}$ Tris- $\mathrm{HCl}, \mathrm{pH} 7.4,150 \mathrm{mM} \mathrm{NaCl}, 1 \mathrm{mM}$ EDTA, $1 \%$ Triton $\mathrm{X}-100,1 \%$ sodium deoxycholate, $0.1 \%$ SDS) containing protease inhibitors. Proteins $(100 \mu \mathrm{g})$ from the supernatant were loaded onto an SDS polyacrylamide gel, following by western blotting analysis to detect the levels of E-cadherin, N-cadherin, occludin, vimentin, twist, snail and $\beta$-actin. The immunoreactive bands were visualized using an ECL system (NEN Life Science Products, Boston, MA) and developed using x-ray films. The amount of protein in each band was quantified using ImageQuant 5.2 (GE Healthcare, Piscataway, NJ).

\section{Immunofluorescence staining}

Immunofluorescence staining was performed as previously described [45]. Briefly, cells seeded on a 4-well chamber slide (Merck Millipore, Darmstadt, Germany) at a density of $1 \times 10^{4}$ cells/well were transfected with $1 \mu \mathrm{g}$ of either pCDNA3.1-CPS1-IT1 or pCDNA3.1 plasmid. Forty-eight hours after transfection, the cells were harvested and fixed in ice-cold acetone for $10 \mathrm{~min}$. The slides were washed 3 times with $1 \times$ PBS, blocked with 5\% goat serum, and incubated with antibodies against Hsp90, vimentin, N-cadherin and E-cadherin (Cell Signaling Technology). Next, the slides were labeled with Alexa Flour 488-conjugated goat anti-rabbit IgG and Alexa Fluor 546-conjugated goat anti-mouse IgG (Invitrogen) and counter-stained with DAPI. The cells were then analyzed using confocal fluorescence microscopy.

\section{Cell proliferation assay}

Cell proliferation capacity was monitored using an xCELLigence real-time cell analyzer (Roche Life Science, Indiana, USA) and examined by a colony formation assay according to the manufacturer's instructions. For the colony formation assay, cells transfected with a plasmid expressing CPS1-IT1 or the empty vector were seeded onto 6-well plates at a density of 500 cells/well and maintained for 12 days in DMEM containing 10\% FBS. The medium was replaced every 3 days. Colonies were fixed with methanol twelve days later and stained with $0.1 \%$ crystal violet (Sigma-Aldrich, St. Louis, MO, USA). Visible colonies were imaged and manually quantified.

\section{Cell migration and invasion assays}

Cell migration activity was analyzed using a wound-healing assay and a transwell migration assay as previously described [12]. For the wound-healing assay, treated SK-Hep1 cells were plated onto 6-well plates and cultured to $90 \%$ confluence. Cells were scraped with a p200 tip (time 0), and the medium was replaced with low-serum culture medium. The migration distances of the cells were measured from images (five fields) taken at the indicated time points.

The migration and invasion abilities of $\mathrm{J} 7$ and SK-Hep1 cells were assessed using ThinCert Tissue Cell Culture Inserts (Greiner Bio-One, Kremsmunster, Austria) containing an 8 - $\mu \mathrm{m}$ mean pore size membrane. For the migration assay, the cells were trypsinized and suspended in serum-free culture medium (DMEM) to a final concentration of $5 \times 10^{5}$ cells $/ \mathrm{ml}$. The lower 
chambers were filled with $500 \mu \mathrm{l}$ of complete medium (DMEM supplemented with 10\% FBS), and 100- $\mu 1$ aliquots of the cells were loaded into each upper well. The chambers were incubated in a humidified 5\% $\mathrm{CO}_{2}$ incubator at $37^{\circ} \mathrm{C}$ for 24 hours. The cells were fixed with $500 \mu \mathrm{l}$ of methanol for 15 minutes; to remove the non-migrating cells, cells on the inner surface of the upper chambers were wiped using cotton swabs. The membrane was washed with $500 \mu \mathrm{l}$ of PBS and stained with $500 \mu \mathrm{l}$ of crystal violet for 20 minutes at room temperature. After the cells were washed with $500 \mu \mathrm{l}$ of PBS, the stained cells were imaged using ImagePro 6.2 software. Counts were obtained from five random fields at $100 \times$ magnification. For the invasion assay, the membrane was coated with $30 \mathrm{mg} / \mathrm{cm}^{2}$ Matrigel (ECM gel, Sigma-Aldrich, St. Louis, MO) to form a matrix barrier. The procedure for the migration assay was the same as described above, except that the migration time was 48 hours.

\section{In vitro transcription and RNA pull-down assay}

In vitro transcription was performed as previously described [46]. Briefly, the pCDNA3.1-CPS1-IT1 plasmid containing a $\mathrm{T} 7$ promoter was linearized by BamHI digestion, purified, and used as a template for in vitro transcription. The template was incubated in ATP, CTP, GTP, and UTP (1 mM each) plus T7 RNA polymerase in $1 \times$ transcription buffer. The in vitro-transcribed RNA was purified using an RNeasy purification kit (Qiagen, Germany), and the transcripts were labeled with biotin using a Thermo Scientific Pierce RNA 3' Desthiobiotinylation Kit (Thermo Fisher Scientific, MA, USA). The RNA-protein binding reaction was performed using freshly harvested SKHep1 cells and a Pierce ${ }^{\mathrm{TM}}$ Magnetic RNA-Protein Pull-Down Kit (Thermo Fisher Scientific, MA, USA). The reaction products were then subjected to mass spectrometry for protein identification.

\section{Protein identification via mass spectrometry}

After protein separation by SDS-PAGE, the gel was stained with EZBlue (Sigma-Aldrich, St. Louis, MO, USA). The detected bands, in addition to the control region in which no proteins were detected, were excised. In-gel tryptic digestion was performed according to the manufacturer's protocol. The tryptic digest was then analyzed by mass spectrometry. Matrixassisted laser desorption ionization-time of flight mass spectrometry was initially performed to identify peptide mass fingerprints. Specific peaks were selected for inclusion in the tandem mass spectrometry analysis to identify the peptide sequences. Proteins were identified using MASCOT software.

\section{RNA immunoprecipitation assay}

Protein-RNA complexes were immunoprecipitated using $3 \mu \mathrm{g}$ of an anti-Hsp90 antibody, and RNA was purified using an RNeasy extraction kit (Qiagen, Hilden, Germany). The anti-KCNH2 antibody was used as a negative control. To detect CPS1-IT1 expression, the extracted RNA was subjected to quantitative real-time RT-PCR using a TaqMan non-coding RNA assay (Applied Biosystems, Foster City, CA, USA).

\section{HIF-1 $\alpha$ activity assay}

HIF-1 $\alpha$ activity was analyzed using a Cignal HIF Reporter assay (Qiagen, Hilden, Germany). Cell lines were seeded in 6-well plates at a density of $3 \times 10^{5}$ cells/ well overnight. The cells were transfected with $1 \mu \mathrm{g}$ of either pCDNA3.1-CPS1-IT1 or pCDNA3.1 plasmid. Twenty-four hours after transfection, the cells were transfected with $1 \mu \mathrm{g}$ HIF-1 reporter mixture. Another 48 hours later, the cells were harvested and subjected to a luciferase assay.

\section{Mice}

Male $\mathrm{BALB} / \mathrm{C}$ nude mice that were 6-8 weeks old (purchased from the National Laboratory Animal Center, Taipei, Taiwan) were housed under pathogen-free conditions with a 12-hour light/12-hour dark schedule and provided autoclaved standard chow and water. The mice were bred at the Animal Center of Chang-Gung Hospital (Taoyuan, Taiwan) according to the Guidelines for the Care and Use of Laboratory Animals (NIH). All experiments related to the animal studies were approved by the Institutional Animal Care and Use Committee (IACUC) at Chang-Gung Hospital.

\section{Tumorigenicity and in vivo metastasis assays}

A total of $1 \times 10^{6}$ cells of the $\mathrm{J} 7$ and SK-Hep1 cell lines, stably expressing the CPS1-IT1 or pCDNA3.1 plasmid, were resuspended in $100 \mu \mathrm{l}$ of saline with $50 \%$ Matrigel (BD Biosciences) and implanted subcutaneously into the left and right flank regions of the mice. Tumor volume growth was recorded weekly using digital calipers. For the in vivo metastasis assay, the same number of transfected cells was injected into the tail vein of the nude mice, which were sacrificed at 6 weeks. Lung metastasis was examined using H\&E staining with a microscope, and the tumor volume was measured in five random fields at $100 \times$ magnification.

\section{Immunohistochemistry}

Tissues were fixed in formalin and embedded in paraffin, and 2- $\mu \mathrm{m}$-thick consecutive sections were cut and mounted onto glass slides. The slides were first 
incubated at $65^{\circ} \mathrm{C}$ for 1 hour and then deparaffinized in xylene, rehydrated in graded ethanol solutions, and finally boiled in Trilogy reagent (Cell Marque, Rocklin, CA) for 10 minutes for antigen retrieval. After washing with $1 \times$ phosphate-buffered saline (PBS), the slides were immersed in $3 \%$ hydrogen peroxide for 10 minutes to suppress endogenous peroxidase activity. After three rinses with $1 \times$ PBS, the sections were subsequently incubated with antibodies against Hsp90, vimentin, N-cadherin and E-cadherin for 1 hour at room temperature. After three rinses with $1 \times \mathrm{PBS}$, the slides were incubated with a biotinylated secondary antibody (Dako, Glostrup, Denmark) for 25 minutes. Following three rinses with $1 \times$ PBS, horseradish-peroxidase conjugated streptavidin was added for 25 minutes at room temperature. Peroxidase activity was detected using 3,3-diaminobenzidine (DAB) (Dako) at room temperature. The slides were then counterstained with hematoxylin.

\section{Statistical analysis}

The original real-time PCR data and data for the western blotting and migration assay analyses were recorded as continuous variants and analyzed using Student's $t$-test. All statistical analyses were performed using SPSS 16.0 and Excel 2007. All statistical tests were two-sided, and p-values $<0.05(*),<0.01(* *)$, or $<0.001$ $(* * *)$ were considered to be significant.

\section{ACKNOWLEDGMENTS}

We would like to thank the Tissue Bank, Microscope Core Laboratory and Clinical Proteomics Core Laboratory at Chang Gung Memorial Hospital, Lin-Kou, Taiwan, for assistance with tissue processing and data analysis. We thank Ying Chen and Tsung-Han Hsieh for excellent technical assistance with this project.

\section{CONFLICTS OF INTEREST} interests.

The authors declare that they have no competing

\section{GRANT SUPPORT}

This work was partially supported by the Ministry of Science and Technology, Taiwan (grant MOST 104-2320-B-182A-009-), and the Chang Gung Medical Research Program, Taiwan (grant CMRPG3D1322).

\section{REFERENCES}

1. Chen CJ, Yang HI, Iloeje UH. Hepatitis B virus DNA levels and outcomes in chronic hepatitis B. Hepatology. 2009; 49: S72-84.
2. Hu DJ, Xing J, Tohme RA, Liao Y, Pollack H, Ward JW, Holmberg SD. Hepatitis B testing and access to care among racial and ethnic minorities in selected communities across the United States, 2009-2010. Hepatology. 2013; 58 : 856-862.

3. Tai DI, Lin SM, Sheen IS, Chu CM, Lin DY, Liaw YF. Long-term outcome of hepatitis B e antigen-negative hepatitis B surface antigen carriers in relation to changes of alanine aminotransferase levels over time. Hepatology. 2009; 49: 1859-1867.

4. Yeh CT, So M, Ng J, Yang HW, Chang ML, Lai MW, Chen TC, Lin CY, Yeh TS, Lee WC. Hepatitis B virusDNA level and basal core promoter A1762T/G1764A mutation in liver tissue independently predict postoperative survival in hepatocellular carcinoma. Hepatology. 2010; 52: 1922-1933.

5. Llovet JM. Liver cancer: time to evolve trial design after everolimus failure. Nat Rev Clin Oncol. 2014; 11: 506-507.

6. Lafaro KJ, Demirjian AN, Pawlik TM. Epidemiology of hepatocellular carcinoma. Surg Oncol Clin N Am. 2015; 24: 1-17.

7. Worns MA, Galle PR. HCC therapies--lessons learned. Nat Rev Gastroenterol Hepatol. 2014; 11: 447-452.

8. Tung-Ping Poon R, Fan ST, Wong J. Risk factors, prevention, and management of postoperative recurrence after resection of hepatocellular carcinoma. Ann Surg. 2000; 232: 10-24.

9. Yanaga K. Current status of hepatic resection for hepatocellular carcinoma. J Gastroenterol. 2004; 39: 919-926.

10. Cech TR, Steitz JA. The noncoding RNA revolutiontrashing old rules to forge new ones. Cell. 2014; 157: 77-94.

11. Ling H, Fabbri M, Calin GA. MicroRNAs and other noncoding RNAs as targets for anticancer drug development. Nat Rev Drug Discov. 2013; 12: 847-865.

12. Wang TH, Lin YS, Chen Y, Yeh CT, Huang YL, Hsieh TH, Shieh TM, Hsueh C, Chen TC. Long non-coding RNA AOC4P suppresses hepatocellular carcinoma metastasis by enhancing vimentin degradation and inhibiting epithelialmesenchymal transition. Oncotarget. 2015; 6: 23342-23357. doi: 10.18632/oncotarget.4344.

13. Jiang J, Gusev Y, Aderca I, Mettler TA, Nagorney DM, Brackett DJ, Roberts LR, Schmittgen TD. Association of MicroRNA expression in hepatocellular carcinomas with hepatitis infection, cirrhosis, and patient survival. Clin Cancer Res. 2008; 14: 419-427.

14. Park JK, Kogure T, Nuovo GJ, Jiang J, He L, Kim JH, Phelps MA, Papenfuss TL, Croce CM, Patel T, Schmittgen TD. MiR-221 silencing blocks hepatocellular carcinoma and promotes survival. Cancer Res. 2011; 71: 7608-7616.

15. Koberle V, Kronenberger B, Pleli T, Trojan J, Imelmann E, Peveling-Oberhag J, Welker MW, Elhendawy M, Zeuzem S, Piiper A, Waidmann O. Serum microRNA-1 and microRNA-122 are prognostic markers in patients 
with hepatocellular carcinoma. Eur J Cancer. 2013; 49: 3442-3449.

16. Giordano S, Columbano A. MicroRNAs: new tools for diagnosis, prognosis, and therapy in hepatocellular carcinoma? Hepatology. 2013; 57: 840-847.

17. Liu Y, Pan S, Liu L, Zhai X, Liu J, Wen J, Zhang Y, Chen $\mathrm{J}$, Shen $\mathrm{H}, \mathrm{Hu} \mathrm{Z}$. A genetic variant in long non-coding RNA HULC contributes to risk of HBV-related hepatocellular carcinoma in a Chinese population. PLoS One. 2012; 7 : e35145.

18. Batista PJ, Chang HY. Long noncoding RNAs: cellular address codes in development and disease. Cell. 2013; 152: 1298-1307.

19. Schonrock N, Harvey RP, Mattick JS. Long noncoding RNAs in cardiac development and pathophysiology. Circ Res. 2012; 111: 1349-1362.

20. Tan $\mathrm{L}$, Yu JT, Hu N, Tan L. Non-coding RNAs in Alzheimer's disease. Mol Neurobiol. 2013; 47: 382-393.

21. Faghihi MA, Modarresi F, Khalil AM, Wood DE, Sahagan BG, Morgan TE, Finch CE, St Laurent G, 3rd, Kenny PJ, Wahlestedt C. Expression of a noncoding RNA is elevated in Alzheimer's disease and drives rapid feed-forward regulation of beta-secretase. Nat Med. 2008; 14: 723-730.

22. Li H, An J, Wu M, Zheng Q, Gui X, Li T, Pu H, Lu D. LncRNA HOTAIR promotes human liver cancer stem cell malignant growth through downregulation of SETD2. Oncotarget. 2015; 6: 27847-27864. doi: 10.18632/ oncotarget. 4443.

23. $\mathrm{Hu} \mathrm{L}, \mathrm{Wu} \mathrm{Y}$, Tan $\mathrm{D}$, Meng $\mathrm{H}$, Wang $\mathrm{K}$, Bai Y, Yang $\mathrm{K}$. Up-regulation of long noncoding RNA MALAT1 contributes to proliferation and metastasis in esophageal squamous cell carcinoma. J Exp Clin Cancer Res. 2015; 34: 7.

24. Ma KX, Wang HJ, Li XR, Li T, Su G, Yang P, Wu JW. Long noncoding RNA MALAT1 associates with the malignant status and poor prognosis in glioma. Tumour Biol. 2015; 36: 3355-3359.

25. Shi XM, Teng F. Up-regulation of long non-coding RNA Sox2ot promotes hepatocellular carcinoma cell metastasis and correlates with poor prognosis. Int J Clin Exp Pathol. 2015; 8: 4008-4014.

26. Zhai X, Zhu H, Wang W, Zhang S, Zhang Y, Mao G. Abnormal expression of EMT-related proteins, S100A4, vimentin and E-cadherin, is correlated with clinicopathological features and prognosis in HCC. Med Oncol. 2014; 31: 970.

27. Shi X, Sun M, Liu H, Yao Y, Song Y. Long non-coding RNAs: a new frontier in the study of human diseases. Cancer Lett. 2013; 339: 159-166.

28. Prensner JR, Chinnaiyan AM. The emergence of lncRNAs in cancer biology. Cancer Discov. 2011; 1: 391-407.

29. Nagaraju GP, Long TE, Park W, Landry JC, TaliaferroSmith L, Farris AB, Diaz R, El-Rayes BF. Heat shock protein 90 promotes epithelial to mesenchymal transition, invasion, and migration in colorectal cancer. Mol Carcinog. 2015; 54: 1147-1158.

30. Mitsiades CS, Mitsiades NS, McMullan CJ, Poulaki V, Kung AL, Davies FE, Morgan G, Akiyama M, Shringarpure R, Munshi NC, Richardson PG, Hideshima T, Chauhan $\mathrm{D}$, et al. Antimyeloma activity of heat shock protein-90 inhibition. Blood. 2006; 107: 1092-1100.

31. Zhang K, Sun X, Zhou X, Han L, Chen L, Shi Z, Zhang A, Ye M, Wang Q, Liu C, Wei J, Ren Y, Yang $\mathrm{J}$, et al. Long non-coding RNA HOTAIR promotes glioblastoma cell cycle progression in an EZH2 dependent manner. Oncotarget. 2015; 6: 537-546. doi: 10.18632/ oncotarget. 2681.

32. Wang F, Ying HQ, He BS, Pan YQ, Deng QW, Sun HL, Chen J, Liu X, Wang SK. Upregulated IncRNA-UCA1 contributes to progression of hepatocellular carcinoma through inhibition of miR-216b and activation of FGFR1/ ERK signaling pathway. Oncotarget. 2015; 6: 7899-7917. doi: 10.18632/oncotarget.3219.

33. Malek E, Jagannathan S, Driscoll JJ. Correlation of long non-coding RNA expression with metastasis, drug resistance and clinical outcome in cancer. Oncotarget. 2014; 5: 8027-8038. doi: 10.18632/oncotarget.2469.

34. Zhang H, Chen Z, Wang X, Huang Z, He Z, Chen Y. Long non-coding RNA: a new player in cancer. J Hematol Oncol. 2013; 6: 37 .

35. Chen X, Lingala S, Khoobyari S, Nolta J, Zern MA, Wu J. Epithelial mesenchymal transition and hedgehog signaling activation are associated with chemoresistance and invasion of hepatoma subpopulations. J Hepatol. 2011; 55: 838-845.

36. Park MY, Kim KR, Park HS, Park BH, Choi HN, Jang KY, Chung MJ, Kang MJ, Lee DG, Moon WS. Expression of the serum response factor in hepatocellular carcinoma: implications for epithelial-mesenchymal transition. Int $\mathbf{J}$ Oncol. 2007; 31: 1309-1315.

37. Liang WC, Fu WM, Wong CW, Wang Y, Wang WM, Hu GX, Zhang L, Xiao LJ, Wan DC, Zhang JF, Waye MM. The lncRNA H19 promotes epithelial to mesenchymal transition by functioning as miRNA sponges in colorectal cancer. Oncotarget. 2015; 6: 22513-22525. doi: 10.18632/ oncotarget. 4154.

38. Geisler S, Coller J. RNA in unexpected places: long noncoding RNA functions in diverse cellular contexts. Nat Rev Mol Cell Biol. 2013; 14: 699-712.

39. Wang X, Arai S, Song X, Reichart D, Du K, Pascual G, Tempst P, Rosenfeld MG, Glass CK, Kurokawa R. Induced ncRNAs allosterically modify RNA-binding proteins in cis to inhibit transcription. Nature. 2008; 454: 126-130.

40. Hellwig S, Bass BL. A starvation-induced noncoding RNA modulates expression of Dicer-regulated genes. Proc Natl Acad Sci U S A. 2008; 105: 12897-12902.

41. Li J, Soroka J, Buchner J. The Hsp90 chaperone machinery: conformational dynamics and regulation by co-chaperones. Biochim Biophys Acta. 2012; 1823: 624-635. 
42. Dixit A, Verkhivker GM. Probing molecular mechanisms of the Hsp90 chaperone: biophysical modeling identifies key regulators of functional dynamics. PLoS One. 2012; 7: e37605.

43. Braconi C, Kogure T, Valeri N, Huang N, Nuovo G, Costinean S, Negrini M, Miotto E, Croce CM, Patel T. microRNA-29 can regulate expression of the long non-coding RNA gene MEG3 in hepatocellular cancer. Oncogene. 2011; 30: 4750-4756.

44. Zhi H, Ning S, Li X, Li Y, Wu W, Li X. A novel reannotation strategy for dissecting DNA methylation patterns of human long intergenic non-coding RNAs in cancers. Nucleic Acids Res. 2014; 42: 8258-8270.

45. Wang TH, Chang JL, Ho JY, Wu HC, Chen TC. EphrinA5 suppresses colon cancer development by negatively regulating epidermal growth factor receptor stability. FEBS J. 2012; 279: 251-263.

46. Wang TH, Li WT, Yu SH, Au LC. The use of 10-23 DNAzyme to selectively destroy the allele of mRNA with a unique purine-pyrimidine dinucleotide. Oligonucleotides. 2008; 18: 295-299. 